\title{
Effects of Coronavirus Pandemic on Young Adults' Ability to Access Health Services and Practice Recommended Preventive Measures
}

\author{
Judith Nalukwago ${ }^{1,3}$, Bolanle Olapeju ${ }^{1}$, Pallen Mugabe ${ }^{1}$, Anna Passaniti $^{1}$, Musa Kimbowa ${ }^{1}$, Arzum Ciloglu ${ }^{1}$, \\ Glory Mkandawire ${ }^{1}$, Richard Kabanda ${ }^{2} \&$ Douglas Storey ${ }^{1}$ \\ ${ }^{1}$ Johns Hopkins University, Center for Communication Programs, Uganda \\ ${ }^{2}$ Ministry of Health, Uganda \\ ${ }^{3}$ Makerere University, Uganda \\ Correspondence: Dr. Judith Nalukwago, Johns Hopkins University Center for Communication Programs. E-mail: \\ nalukwagoj@jhccpug.org;
}

Received: June 9, 2021 Accepted: September 5, 2021 Online Published: September 20, 2021

doi:10.5539/gjhs.v13n11p14 URL: https://doi.org/10.5539/gjhs.v13n11p14

\begin{abstract}
Given the limited attention to young adults as key contributors to the spread of COVID-19 in Uganda, this study examines the effects of the outbreak on the ability of young adults aged 18-29 to access health services and practice preventive measures. A national population-based mobile phone survey was conducted in December 2020. Multivariable regression analyses were used to explore the effect of the COVID-19 pandemic on access to health care services. Control variables included region, education level, parity, and source of health information. The majority (98\%) perceived COVID-19 as a serious threat to Ugandans. Although the majority reported handwashing (97\%) and masking (92\%), fewer respondents avoided shaking hands (39\%), ensured physical distancing (57\%), avoided groups of more than four people (43\%), stayed home most days $(30 \%)$, avoided touching eyes, nose, and mouth (14\%), and practiced sneezing/coughing into their elbow (7\%). Participants noted that the COVID-19 pandemic affected their ability to access family planning (40\%), HIV (49\%), maternal health $(55 \%)$, child health $(56 \%)$, and malaria $(63 \%)$ services. The perceived effect of the COVID-19 pandemic on services was higher for those in the Northern region $(\mathrm{OR}=2.00,95 \% \mathrm{CI} 1.00-4.02)$, those with higher education $\mathrm{OR}=2.26,95 \% \mathrm{CI} 1.28-3.99)$, those with five plus children $(\mathrm{OR}=2.05,95 \% \mathrm{CI} 0.92-4.56)$, and those who trust radio for COVID-19 information (OR=1.65, 95\% CI 1.01-2.67). The findings show the pragmatic importance of understanding the dynamic characteristics and behavioral patterns of young adults in the context of COVID-19 to inform targeted programming.
\end{abstract}

Keywords: Coronavirus, COVID-19, behavior, health services, social behavior change, sub-Saharan Africa, Uganda, young adults

\section{Introduction}

Coronavirus disease 2019 (COVID-19) is an infectious and transmissible disease that spreads primarily through droplets of saliva or discharge from the nose when an infected person coughs or sneezes (WHO, 2021; Shereen, Khan, Kazmi, Bashir, \& Siddique, 2020). COVID-19 was declared a global pandemic by the World Health Organization (WHO) on March 11, 2020, and Uganda declared its first case on March 21, 2020 (Feyisa 2021; WHO 2020; Orgilés, Morales, Delvecchio, Mazzeschi, \& Espada, 2020; Oosterhoff, Palmer, Wilson, \& Shook, 2020). The WHO declaration brought with it global panic, fear of contracting the disease, and the disruption of social life. As part of the measures to curb the spread of the pandemic, stringent government restrictions were instituted, including a total lockdown from March 30, 2020, to June 22, 2020, closure of schools and business centers such as markets, arcades, bars, hotels, sports grounds, prohibition of gatherings of 10 or more people, country-wide travel prohibition, closure of cross border travels except cargo transportation, closure of public transport, a 14-day quarantine of returning travelers, and curfew running from 19:00 to 06:30 hours (Matovu, Kabwama, Ssekamatte, Ssenkusu, \& Wanyenze, 2021; Linnemayr et al., 2020). Moreover, the government also promoted infection prevention measures such as washing hands often with soap and water for at least 20 seconds, use of hand sanitizers, and avoiding touching eyes, nose, and mouth with unwashed hands (Bukuluki, Mwenyango, Katongole, Sidhva, \& Palattiyil, 2020). The widespread social and economic effects of the COVID-19 pandemic in 
Uganda have likely affected access to, and perceptions of, health care services. This could partly be linked to the stringent restrictions that came with the pandemic.

As cases of COVID-19 continue to soar, with 51,006 confirmed cases and 374 deaths in the country by June 5, 2021 (MOH, 2021), there is still limited attention on young adults as key contributors to the spread of the pandemic in Uganda, and notably, how the pandemic has affected their access to health services and practice of prevention measures.

Young adults in Uganda typically encounter barriers to accessing health services including family planning (Adams, Salazar, \& Lundgren, 2013), HIV testing, and treatment (Small, Nikolova, Zhou, \& Okumu, 2021; MacCarthy et al., 2018). As Nagata (2020) notes, young adults are generally assumed to be healthy, yet they may be a key population to turn the tide of COVID-19 transmission, because of their low risk perception. Although there is data on COVID-19 cases, the public is not regularly updated on age specific persons found to be positive in Uganda. Disaggregation of data may in one way affect the risk perception of certain groups of the population including young adults. The young adults are a potentially vulnerable population and need to be uniquely supported to adhere to public health guidance to prevent the spread of the pandemic and to access health services.

The present study examines how the COVID-19 pandemic has affected the ability to access health services and practice of preventive measures among young adults aged 18-29 in Uganda. Specifically, we explore young adults' perceived threat of COVID-19, measures taken to control the spread of the pandemic, the perceived effect of the COVID-19 pandemic on their ability to access health care services, and their exposure to COVID-19 messages, including the messages seen or heard and sources of health information. The study provides insights that inform the targeted design and implementation of health promotion including social and behavior change interventions aimed at curbing the spread of the pandemic among this priority audience and beyond.

\section{Methods}

\subsection{Study Design}

A cross-sectional population-based mobile phone survey was conducted in December 2020 due to restrictions on in-person data collection during the COVID-19 pandemic. The survey covered the four regions of Uganda including Central, Eastern, Northern, and Western.

\subsection{Study Participants and Sampling Procedure}

The survey collected data from women and men aged 18-49 using Computer Assisted Telephone Interviewing (CATI) techniques. This study focuses on only the subsample of young adults aged 18-29. The sample size calculation assumed a prevalence of .50 (for maximum variability across multiple health behaviors), .80 power, 0.05 alpha, 0.075 delta, and a design effect of 1.5. Based on these parameters, a total sample of 1400 individuals were recruited, and evenly distributed among men and women. A two-stage sampling approach was used. Within each region, we randomly selected households with probability proportional to population size of the enumeration areas (EAs), using the most recent 2016 census sampling frame obtained from the Uganda Bureau of Statistics. Then, a team of trained researchers worked with community leaders, including local council chairpersons (LC1s) and village health teams (VHTs), to collect household-level data on cell phone ownership. For each identified household with a cell phone, the contact number, gender, age, and preferred language of the cell phone owner were noted. The information was used to generate a sampling frame of representative phone numbers across the four regions that were used for the interviews. The inclusion criteria for the study participants were: women and men aged 18-49 years, residents in one of the four regions of Uganda, with ability to communicate effectively in the local language or English, provide informed consent, and access a mobile phone either personally or through someone in the household. The eligible participants were systematically contacted and recruited into the study. From each EA, 8 households were randomly selected and an adult member of the household was interviewed. This manuscript focuses on data from the 432 young adults aged 18-29 who were interviewed.

\subsection{Study Variables or Measures}

For socio-demographics, the survey assessed age based on self-reported age in years at the time of the survey (subsequently dichotomized into 18-24 versus 25-29 in order to compare younger and older cohorts of the young adult subsample), sex (male versus female), education level (less than primary schooling, primary or some secondary schooling, completed secondary school or higher), region (Central, Eastern, Northern, or Western), residence (rural or urban), and number of children under participants' care (subsequently categorized as none, one to four, and five or more). The participants' perceived threat of COVID-19 was assessed using the question: do you 
agree or disagree that COVID-19 poses a real threat to Ugandans? Responses were on a 3-point Likert scale of agree, neither agree nor disagree, and disagree. The extent to which COVID-19 affected access to health care services was assessed with the following question: to what extent has the pandemic affected your ability to access [name health service] in your area. The question was repeated for each type of health service of interest: family planning, HIV, maternal health, child health, and malaria. Responses were on a 3-point Likert scale of not at all, to some extent, and to a great extent. Participants also were asked if they took any action to avoid the spread of COVID-19 (yes versus no) and then were asked which specific measures were taken to curb the spread of the pandemic. Measures included hand washing; masking; social distancing; avoiding hand shaking; avoiding touching eyes, nose, and mouth; staying home; and sneezing or coughing inside of the elbow. Participants also were asked if they had seen or heard any message on COVID-19 (yes versus no), what specific messages they recalled and how many times they recalled seeing or hearing the specific messages $(1,2$, or 3 or more times). Finally, participants were asked about their preferred or trusted sources of health information (responses included social media, television, radio, newspapers, health worker, community leaders, or other sources).

\subsection{Ethical Approval}

Ethical approval for the study was obtained from the Johns Hopkins School of Public Health Institutional Review Board in the United States of America, under reference 13837, and in Uganda from the Makerere School of Public Health Higher Degrees, Research and Ethics Committee, under reference 864. The study was also registered with the Uganda National Council of Science and Technology. Verbal informed consent was sought from each participant before the interviews were undertaken and documented by study staff.

\subsection{Data Analysis}

Analyses were carried out using Stata 14 and SPSS 25. Tests of association (Chi-square) explored participants' characteristics and outcomes of interest. Multivariable regression analyses were used to explore the effect of COVID-19 pandemic on access to health care services by young adults aged 18-29. Covariates in the model included region, education level, parity, and source of health information. We assessed the model to be a good fit using Hosmer and Lemeshow's goodness-of-fit test at $\mathrm{p}>0.1$.

\section{Results}

\subsection{Socio-Demographics}

Our analysis included a total of 432 young adults aged $18-29$ years. Of these, $47 \%$ were male and $53 \%$ female. The majority $(60 \%)$ were in the age group of $25-29$. Thirty percent of the participants were from Eastern region, and $71 \%$ from rural residence. Forty-one percent had primary or some secondary schooling, 33\% had completed secondary school or higher education, and $26 \%$ had less than primary schooling. Overall, $72 \%$ had one to four children under their care. Notably, more participants aged 25-29 (77\%) reported having one to four children under their care (Table 1).

Table 1. Socio-demographics characteristics of participants

\begin{tabular}{|c|c|c|c|c|}
\hline \multirow{3}{*}{ Measure } & \multicolumn{2}{|l|}{ Age group } & \multirow{3}{*}{$\begin{array}{l}\text { Total } \\
N=432(100 \%)\end{array}$} & \multirow{3}{*}{$P$} \\
\hline & $18-24$ & $25-29$ & & \\
\hline & $N=171(40 \%)$ & $\mathrm{N}=261(60 \%)$ & & \\
\hline \multicolumn{5}{|l|}{ Gender } \\
\hline Male & $42 \%$ & $50 \%$ & $47 \%$ & \multirow{2}{*}{0.100} \\
\hline Female & $58 \%$ & $50 \%$ & $53 \%$ & \\
\hline \multicolumn{5}{|l|}{ Region } \\
\hline Central & $19 \%$ & $25 \%$ & $23 \%$ & \multirow{4}{*}{0.002} \\
\hline Eastern & $40 \%$ & $23 \%$ & $30 \%$ & \\
\hline Northern & $23 \%$ & $26 \%$ & $25 \%$ & \\
\hline Western & $17 \%$ & $26 \%$ & $22 \%$ & \\
\hline
\end{tabular}




\begin{tabular}{lllll}
\hline $\begin{array}{l}\text { Residence } \\
\text { Urban }\end{array}$ & $29 \%$ & $30 \%$ & $29 \%$ & 0.850 \\
Rural & $71 \%$ & $70 \%$ & $71 \%$ & \\
\hline Education level & & & & \\
$\quad$ Less than Primary schooling & $25 \%$ & $26 \%$ & $26 \%$ & 0.033 \\
$\quad$ Primary or some secondary schooling & $48 \%$ & $37 \%$ & $41 \%$ & \\
$\quad$ Completed secondary school or higher & $27 \%$ & $37 \%$ & $33 \%$ & $<0.001$ \\
\hline Number of children under their care & & & $18 \%$ & \\
$\quad$ None & $28 \%$ & $11 \%$ & $72 \%$ & $10 \%$ \\
$\quad$ One - four & $64 \%$ & $77 \%$ & $12 \%$ & \\
$\quad$ Five or more $(5+)$ & $8 \%$ & &
\end{tabular}

\subsection{Perceived Threat of COVID-19 and Measures Taken to Control the Spread of the Pandemic}

\subsubsection{Perceived Threat of COVID-19}

Overall, $98 \%$ of the participants perceived COVID-19 as a real threat to Ugandans. Table 2 indicates that young adults aged 18-24 were slightly less likely to perceive COVID-19 as a real threat to Ugandans compared to adults aged 25-29 years, particularly in Central and Western regions.

\subsubsection{Measures Taken to Control the Spread of COVID-19}

Overall, $99 \%$ of the participants reported that they took at least one action to control the spread of COVID-19 in the past six months preceding the survey. Table 2 shows that the majority across age groups reported that they had cleaned hands with soap/sanitizer more often, $96 \%$ for $18-24$ years, and $97 \%$ for $25-29 \%$. Similarly, the majority indicated that they always wear a face mask when outside, $93 \%$ for $18-24$ years, $91 \%$ for $25-29$ years. However, overall, the actions on avoiding shaking hands/hugging people (39\%), practicing social distancing (57\%), avoiding groups of more than 4 people (43\%), and staying home most days and only moving outside if necessary (30\%), were low across all age groups. Similarly, the actions on avoiding touching soft parts of the body such as eyes/nose/mouth (14\%), sneezing/coughing in the inside of the elbow (7\%), and staying at or camping at the workplace if necessary ( $4 \%)$ were very low.

By age group, the actions of avoiding shaking hands/hugging people (38\%), avoiding touching soft parts of the body such as eyes/nose/mouth (11\%), staying home most days and only moving outside if necessary (28\%), and sneezing/coughing in the inside of the elbow (5\%), and staying at or camping at the workplace if necessary (5\%) were low for those aged 18-24. Avoiding touching soft parts of the body such as eyes/nose/mouth (15\%) sneezing/coughing in the inside of the elbow (8\%), and staying at or camping at the workplace if necessary (3\%) were low for those aged 25-29 years (Table 2). 
Table 2. Measures taken to control the spread of COVID-19

\begin{tabular}{|c|c|c|c|c|}
\hline \multirow{3}{*}{ Measure } & \multicolumn{2}{|l|}{ Age group } & Total & \multirow{3}{*}{$\boldsymbol{P}$} \\
\hline & $18-24$ & $25-29$ & \multirow{2}{*}{$\begin{array}{l}N= \\
(100 \%)\end{array}$} & \\
\hline & $\begin{array}{l}N=171 \\
(40 \%)\end{array}$ & $\begin{array}{l}\mathrm{N}=261 \\
(60 \%)\end{array}$ & & \\
\hline \multicolumn{5}{|l|}{ Perceived COVID-19 threat as a real threat to Ugandans } \\
\hline Central & $94 \%$ & $98 \%$ & $97 \%$ & 0.266 \\
\hline Eastern & $97 \%$ & $98 \%$ & $98 \%$ & 1.000 \\
\hline Northern & $98 \%$ & $97 \%$ & $97 \%$ & 1.000 \\
\hline Western & $93 \%$ & $100 \%$ & $98 \%$ & 0.089 \\
\hline \multicolumn{5}{|l|}{$\begin{array}{l}\text { Took any action to avoid/curb the spread or contracting Corona virus } \\
\text { in the past six months }\end{array}$} \\
\hline Yes & $99 \%$ & $99 \%$ & $99 \%$ & 1.000 \\
\hline \multicolumn{5}{|l|}{ Measures taken to control the spread of COVID-19 } \\
\hline Clean hands with soap/sanitizer more often & $96 \%$ & $97 \%$ & $97 \%$ & 0.799 \\
\hline Wear a face mask when outside and all the time & $93 \%$ & $91 \%$ & $92 \%$ & 0.594 \\
\hline Avoid shaking hands/hugging people & $38 \%$ & $40 \%$ & $39 \%$ & 0.730 \\
\hline Practice social distancing (Keep $2 \mathrm{~m} / 6 \mathrm{ft}$ a part) & $55 \%$ & $58 \%$ & $57 \%$ & 0.579 \\
\hline Avoid groups of more than 4 people $(>4)$ & $42 \%$ & $44 \%$ & $43 \%$ & 0.657 \\
\hline Avoid touching soft parts of the body such as eyes/nose/mouth & $11 \%$ & $15 \%$ & $14 \%$ & 0.253 \\
\hline Stay home most days and only move outside if necessarily & $28 \%$ & $31 \%$ & $30 \%$ & 0.429 \\
\hline Sneeze/cough in the inside of the elbow & $5 \%$ & $8 \%$ & $7 \%$ & 0.171 \\
\hline Stay at or camp at the workplace if necessary & $5 \%$ & $3 \%$ & $4 \%$ & 0.165 \\
\hline
\end{tabular}

\subsection{Factors Associated with the Effect of COVID-19 Pandemic on Access to Health Care Services}

Overall, the participants indicated that COVID-19 affected their ability to access health services including family planning (40\%), HIV (49\%), maternal health (55\%), child health (56\%), and malaria (63\%). Table 3 shows that the odds of reporting that COVID-19 greatly affected their ability to access family planning were higher for those who trusted radio as a source of information (OR=1.65, 95\% CI $1.01-2.67)$. The odds of reporting the same for HIV care and support services were higher for those in the Northern region ( $\mathrm{OR}=1.76,95 \%$ CI $0.96-3.23)$. Similarly, the odds of reporting that COVID-19 greatly affected their ability to access HIV care and support services were higher for those who had primary or some secondary schooling $(\mathrm{OR}=1.98,95 \% \mathrm{CI} 1.17$ - 3.35) and those who completed secondary $(\mathrm{OR}=2.26,95 \% \mathrm{CI} 1.28$ - 3.99). The odds of reporting the same for maternal health services were higher for those who had 5 or more children $(\mathrm{OR}=2.05,95 \%$ CI $0.92-4.56)$. Similarly, the odds of reporting that COVID-19 greatly affected their ability to access child health services were higher for those in the Northern region $(\mathrm{OR}=1.79,95 \% \mathrm{CI} 0.90-3.58)$ and those who trusted radio as their source of information $(\mathrm{OR}=1.67,95 \%$ CI $1.03-2.70$ ). The odds of reporting the same for malaria services were higher for those in the Northern region $(\mathrm{OR}=2.00,95 \% \mathrm{CI} 1.00-4.02)$ as indicated in Table 3. 
Table 3. Factors associated with the effect of COVID-19 pandemic on access to health services

\begin{tabular}{|c|c|c|c|c|c|}
\hline \multirow[b]{2}{*}{ Predictor } & \multicolumn{5}{|c|}{$\begin{array}{l}\text { Perceived effect of COVID-19 on Health Services } \\
\text { aOR }(95 \% \text { CI })\end{array}$} \\
\hline & $\begin{array}{l}\text { Family } \\
\text { Planning }\end{array}$ & HIV & $\begin{array}{l}\text { Maternal } \\
\text { Health }\end{array}$ & Child Health & Malaria \\
\hline \multicolumn{6}{|l|}{ Age group } \\
\hline $25-29$ (ref) & 1.00 & & 1.00 & 1.00 & \\
\hline $18-24$ & $\begin{array}{l}1.16 \\
(0.76-1.76)\end{array}$ & & $\begin{array}{l}1.18 \\
(0.77-1.80)\end{array}$ & $\begin{array}{l}1.30 \\
(0.85-1.99)\end{array}$ & \\
\hline \multicolumn{6}{|l|}{ Gender } \\
\hline Male (ref) & 1.00 & 1.00 & 1.00 & & 1.00 \\
\hline Female & $\begin{array}{l}0.73 \\
(0.49-1.10)\end{array}$ & $\begin{array}{l}0.71 \\
(0.47-1.07)\end{array}$ & $\begin{array}{l}0.74 \\
(0.49-1.10)\end{array}$ & & $\begin{array}{l}0.80 \\
(0.53-1.20)\end{array}$ \\
\hline \multicolumn{6}{|l|}{ Region } \\
\hline Central (ref) & 1.00 & 1.00 & 1.00 & 1.00 & 1.00 \\
\hline Eastern & $\begin{array}{l}0.62 \\
(0.34-1.14)\end{array}$ & $\begin{array}{l}0.57 * * \\
(0.32-1.00)\end{array}$ & $\begin{array}{l}0.84 \\
(0.46-1.52)\end{array}$ & $\begin{array}{l}0.77 \\
(0.41-1.48)\end{array}$ & $\begin{array}{l}1.55 \\
(0.81-2.97)\end{array}$ \\
\hline Northern & $\begin{array}{l}1.33 \\
(0.72-2.44)\end{array}$ & $\begin{array}{l}1.76^{*} \\
(0.96-3.23)\end{array}$ & $\begin{array}{l}1.65 \\
(0.88-3.09)\end{array}$ & $\begin{array}{l}1.79 * \\
(0.90-3.58)\end{array}$ & $\begin{array}{l}2.00 * \\
(1.00-4.02)\end{array}$ \\
\hline Western & $\begin{array}{l}1.27 \\
(0.69-2.35)\end{array}$ & $\begin{array}{l}1.26 \\
(0.68-2.32)\end{array}$ & $\begin{array}{l}1.39 \\
(0.75-2.56)\end{array}$ & $\begin{array}{l}0.94 \\
(0.50-1.79)\end{array}$ & $\begin{array}{l}1.52 \\
(0.79-2.92)\end{array}$ \\
\hline
\end{tabular}

\section{Education level}

\begin{tabular}{|c|c|c|}
\hline Less than primary (ref) & 1.00 & 1.00 \\
\hline $\begin{array}{l}\text { Primary or some secondary } \\
\text { schooling }\end{array}$ & $\begin{array}{l}1.98^{* *} \\
(1.17-3.35)\end{array}$ & $\begin{array}{l}0.91 \\
(0.54-1.53)\end{array}$ \\
\hline Completed secondary or higher & $\begin{array}{l}2.26^{* * *} \\
(1.28-3.99)\end{array}$ & $\begin{array}{l}1.43 \\
(0.80-2.53)\end{array}$ \\
\hline
\end{tabular}

\begin{tabular}{|c|c|c|}
\hline \multicolumn{3}{|c|}{$\begin{array}{l}\text { Parity (number of children } \\
\text { under one's care) }\end{array}$} \\
\hline No children (ref) & 1.00 & 1.00 \\
\hline 1-4 children & $\begin{array}{l}1.48 \\
(0.86-2.56)\end{array}$ & $\begin{array}{l}1.47 \\
(0.84-2.56)\end{array}$ \\
\hline 5 or more children & $\begin{array}{l}2.05^{*} \\
(0.92-4.56)\end{array}$ & $\begin{array}{l}1.04 \\
(0.47-2.30)\end{array}$ \\
\hline
\end{tabular}




\section{Trusted source of information}

\begin{tabular}{|c|c|c|c|c|c|}
\hline Not trusted & 1.00 & & 1.00 & 1.00 & 1.00 \\
\hline Radio & $\begin{array}{l}1.65 * * \\
(1.01-2.67)\end{array}$ & & $\begin{array}{l}1.48 \\
(0.92-2.38)\end{array}$ & $\begin{array}{l}1.67 * * \\
(1.03-2.70)\end{array}$ & $\begin{array}{l}1.50 \\
(0.91-2.47)\end{array}$ \\
\hline TV & & $\begin{array}{l}0.68 \\
(0.43-1.09)\end{array}$ & & & $\begin{array}{l}1.49 \\
(0.87-2.54)\end{array}$ \\
\hline Health worker & & & $\begin{array}{l}0.70 \\
(0.45-1.08)\end{array}$ & & \\
\hline
\end{tabular}

Note. ${ }^{* * *} \mathrm{p}<0.01, * * \mathrm{p}<0.05, * \mathrm{p}<0.1$, aOR $=$ adjusted Odds Ratio, $\mathrm{CI}=$ Confidence Interval.

\subsection{Exposure to COVID-19 Messages and Sources of Information}

\subsubsection{Participants Who Had Seen or Heard Messages on COVID-19}

Overall, $99 \%$ of the participants had seen or heard a message on COVID-19 in the past six months preceding the survey. Table 4 indicates that $97 \%$ had seen or heard the COVID-19 messages several times [ 3 or more times]. The majority had seen or heard a message on frequently washing hands with soap and running water for at least 20 seconds (88\%), maintaining a 2-meter distance from everyone especially when one leaves home (82\%), always wearing a mask when going to public places $(73 \%)$, and avoiding crowded places $(60 \%)$. However, smaller proportions had seen or heard a message on avoiding shaking hands or hugging people (42\%), avoiding touching eyes, mouth, nose, and ears (26\%), and not stigmatizing people who have recovered from COVID (2\%). By age group, about one-quarter among 18-24 (26\%) and 25-29 (26\%) year old participants had seen or heard a message on avoiding touching eyes, mouth, and nose, but only $1 \%$ and $3 \%$ respectively indicated the same for not stigmatizing people who have recovered from COVID-19.

\subsubsection{Sources of COVID-19 Information}

Most participants had heard COVID-19 messages on radio (90\%), while fewer proportions had heard or seen messages on TV (46\%), newspapers (8\%), telephone messages (48\%), print materials such as brochures (5\%), and social networking sites including Facebook, Twitter $(10 \%)$ as indicated in Table 4 . The majority (71\%) reported that radio is their most trusted source of health information followed by health workers $(66 \%)$, with social media $(10 \%)$ and newspapers $(5 \%)$ being the least trusted.

Additionally, the majority (72\%) reported that they listen to radio every day and $16 \%$ do so a few times a week. Twenty-eight percent indicated that they watch TV every day, and $18 \%$ do so a few times a week. Similarly, $14 \%$ check the internet every day, and $11 \%$ do so a few times a week.

Table 4. Exposure to COVID-19 messages and sources of health information

\begin{tabular}{|c|c|c|c|c|}
\hline \multirow{3}{*}{ Measure } & \multicolumn{2}{|l|}{ Age group } & \multirow{3}{*}{$\begin{array}{l}\text { Total } \\
N=432 \\
(100 \%)\end{array}$} & \multirow[t]{3}{*}{$P$} \\
\hline & $18-24$ & $25-29$ & & \\
\hline & $\begin{array}{l}N=171 \\
(40 \%)\end{array}$ & $\begin{array}{l}N=261 \\
(60 \%)\end{array}$ & & \\
\hline \multicolumn{5}{|c|}{ Times they recall seeing or hearing the Corona virus messages } \\
\hline Once & $1 \%$ & $1 \%$ & $1 \%$ & \\
\hline Twice & $3 \%$ & $2 \%$ & $2 \%$ & 0.532 \\
\hline Several times [ 3 or more times] & $96 \%$ & $97 \%$ & $97 \%$ & \\
\hline
\end{tabular}




\section{COVID-19 messages seen or heard}

Maintain a 2-meter distance from everyone especially when you leave home

$\begin{array}{llll}81 \% & 82 \% & 82 \% & 0.680 \\ 89 \% & 87 \% & 88 \% & 0.422 \\ 48 \% & 55 \% & 52 \% & 0.156 \\ 46 \% & 40 \% & 42 \% & 0.155 \\ 26 \% & 26 \% & 26 \% & 0.944 \\ 58 \% & 62 \% & 60 \% & 0.411 \\ 66 \% & 78 \% & 73 \% & 0.006 \\ 1 \% & 3 \% & 2 \% & 0.094\end{array}$

Frequently wash your hands with soap and running water for at least 20 seconds

Use an alcohol-based hand sanitizer

Do not shake hands or hug anyone

Avoid touching your eyes, mouth, nose, and ears

Avoid crowded places

Always wear a mask when going to public places

Don't stigmatize people who have recovered from COVID-19

Where the COVID-19 messages were seen or heard

\section{Television}

Radio

Newspapers

Websites

Mobile and telephone

Hard copy printed materials include brochures such as information, education and communication materials.

Social networking sites include Facebook, LinkedIn, GooglePlus

Community and Microblogging includes Twitter, YouTube, TikTok, Vimeo

Messaging platforms include WhatsApp and WeChat

Trusted source of health information

Social media (Facebook, WhatsApp, Twitter)

Television

Radio

Newspapers

Health worker

Community leader

\begin{tabular}{llll}
$49 \%$ & $44 \%$ & $46 \%$ & 0.404 \\
$92 \%$ & $89 \%$ & $90 \%$ & 0.229 \\
$6 \%$ & $10 \%$ & $8 \%$ & 0.130 \\
$1 \%$ & $2 \%$ & $2 \%$ & 0.708 \\
$40 \%$ & $52 \%$ & $48 \%$ & 0.017 \\
$2 \%$ & $7 \%$ & $5 \%$ & 0.035 \\
$7 \%$ & $12 \%$ & $10 \%$ & 0.078 \\
$2 \%$ & $4 \%$ & $3 \%$ & 0.392 \\
$4 \%$ & $7 \%$ & $6 \%$ & 0.133 \\
\hline $9 \%$ & & & \\
\hline $30 \%$ & $10 \%$ & $10 \%$ & 0.589 \\
$71 \%$ & $29 \%$ & $29 \%$ & 0.808 \\
$4 \%$ & $71 \%$ & $71 \%$ & 0.986 \\
$63 \%$ & $6 \%$ & $5 \%$ & 0.290 \\
$25 \%$ & $67 \%$ & $66 \%$ & 0.405 \\
\hline
\end{tabular}

\section{Discussion}

This study aimed at obtaining a deeper understanding of the effect of the COVID-19 pandemic on the ability to access health services and practice of preventive behaviors among young adults, specifically focusing on the perceived risk of COVID-19, measures taken to control the spread of the pandemic, the associated effects of the pandemic on access to health services, exposure to COVID-19 messages, and sources of information. The prevailing perception that the COVID-19 pandemic significantly influenced access to health services among young adults in Uganda could partly be explained by the government restrictions, some of which are still in effect, such as curfew from 21:00 to 05:30 hours, closure of schools and churches, prohibition of large gatherings, and closure of business centers such as bars, discos, cinemas. Additionally, young adults' access to services during the COVID-19 pandemic may also be influenced by structural and logistical factors. Studies found that the associated effects of the COVID-19 pandemic on access to health care services are related to lack of or insufficient money for transportation, police violence while enforcing the lockdown poses restrictions on clients' travel to health facilities for services, perceived low quality of services resulting in stock outages and self-medication, and perceptions of potential risks of exposure to COVID-19 while travelling to and/or at the health facility (Linnemayr et al., 2020; Dyer et al., 2020; Sherrard-Smith et al., 2020; Lindberg, Bell, \& Kantor, 2020). These factors could partly explain the finding in the present study. 
In this study, the majority of young adults perceived COVID-19 as a threat to Ugandans, consistent with the U-LEARN (2020) study. From our study, almost all young adults claimed that they took at least one action to control the spread of COVID-19 including hand washing and wearing face masks, but fewer young adults reported avoiding hand shaking, social distancing, avoiding groups of more than 4 people, avoiding touching eyes, nose and mouth, and sneezing inside the elbow. This finding is consistent with other studies which found that relatively fewer young adults practiced physical distancing (Feyisa, 2021; Varol et al., 2021; Babalola et al., 2020). These findings point to the need to strengthen health education interventions including working with youth champions to promote personal responsibility in the uptake of the recommended preventive measures. Our findings further indicate that the reluctancy of young adults to practice the COVID-19 prevention measures is linked to the low COVID-19 risk perception for their age group, low education levels, and limited access to information on COVID-19. Similarly, other studies point to the low income levels, community paying less attention to the disease, and limited exposure to information on how to practice the preventive measures in the youths' settings (Matovu et al., 2021; Olum, Chekwech, Wekha, Nassozi, \& Bongomin, 2020; Abdelhafiz et al., 2020). With the current rising cases of COVID-19 among young adults in Uganda, our findings point to the need to intensify risk communication by putting a face to COVID-19 such as showing live examples of COVID-19 patients in hospital, using testimonies of recovered COVID-19 patients, and showing the economic burden caused by the pandemic. Our study also found that females were more likely to practice the recommended measures to control the spread of the pandemic than males, a finding which is consistent with that of Zhong et al., (2020) and Ningsih, Eka, \& Danal, (2021). Thus, working with youth female positive deviants as champions to the cause of promoting the practice of preventive measures is vital.

Furthermore, our study found that almost all participants had seen or heard messages on COVID-19 several times. Radio was the most common and trusted source of COVID-19 information among young adults, followed by health workers. Mobile and telephone were slightly below average as a source of information. However, newspapers, messaging platforms, and social media were the least trusted sources of information. These findings are consistent with other studies where radio, health workers, and TV are preferred sources of information (Usman et al., 2020). However, the limited internet connectivity in many parts of Uganda and sub-Saharan Africa poses a challenge to the consistent use of phones and social media to access information by the populace. Therefore, it is imperative to address the internet connectivity challenges to harness the opportunities presented by the constantly growing electronic or digital technologies.

\subsection{Implications for Programming}

Our findings point to the need to strengthen targeted health promotion interventions that motivate young adults to practice the recommended preventive measures to curb the spread of the pandemic and improve their ability to access health services. Health promotion and education messages should be intensified using multiple channels of communication to increase risk perceptions among young adults, and promote the practice of COVID-19 prevention measures. It is imperative to use the most common and trusted sources of information - in this case, radio and health workers - to reach young adults with COVID-19 information. Also, programs should explore or leverage new opportunities presented by evolving technologies, including promoting the use of social media platforms to share health information across age groups. Qualitative research should be done to get deeper insights into the factors that affect young adults' ability to access health services in the midst of the pandemic. It is also important to understand better the challenges that young adults face in accessing health information and specific health services, and what hinders them from practicing the recommended COVID-19 preventive measures. Additionally, intensifying advocacy efforts and allocating funding to develop interventions that foster community engagement in developing contextual and practical solutions that address the barriers to accessing health service are imperative. The advocacy efforts should collaboratively engage policymakers, community leaders, parents, and health workers to strengthen community response to the pandemic. More so, targeted efforts should be made to address the barriers occurring at the structural, social, economic, and environmental levels - such as the impact of curfew laws - that make it difficult for young adults to practice the recommended prevention measures and access health services.

\subsection{Study Limitations}

This study had some limitations. Behaviors were self-reported which made over-or under-reporting of certain health behaviors more likely due to social desirability and recall bias. Nonetheless, the self-reported data provided practical insights into areas for strengthening in programming. The study also relied on a mobile phone survey approach which has limitations where some subgroups of the population have limited access to mobile phone technologies. Since the study required access to a mobile phone, it may not accurately represent vulnerable groups such as youth, with lower phone access. 


\section{Conclusion}

Young adults are key contributors to the spread of COVID-19; thus, they need to be uniquely supported to access health services and adhere to the public health prevention guidelines. The majority of participants in our study indicated that COVID-19 has affected their access to health services. This shows the pragmatic importance of understanding the dynamic characteristics and behavioral patterns of young adults in the context of COVID-19 to inform targeted programming. Our findings also indicate that although the majority claimed that they took at least one action to prevent the spread of COVID-19, fewer participants avoided shaking hands, ensured physical distancing, avoided groups of more than 4 people, stayed home most of the days, avoided touching eyes, nose, and mouth, and sneezing/coughing in the inside of the elbow. The findings show the need to intensify health promotion as well as social and behavior change interventions alongside structural interventions that address challenges to the access of health services and promote the practice of preventive measures.

\section{Acknowledgements}

The authors wish to thank USAID Uganda for funding the research activities through Johns Hopkins University Center for Communication Programs. We also thank the USAID/Social and Behavior Change Activity (SBCA) staff who contributed to the overall study design, data collection, and analysis including, Isaac Musoke, Emmanuel Kayongo, and Leanne Wolff. And thanks to Hatchile Consult Ltd for supporting the data collection exercise.

\section{Competing Interests Statement}

The authors declare that there are no competing conflicts of interest.

\section{References}

Abdelhafiz, A. S., Mohammed, Z., Ibrahim, M. E., Ziady, H. H., Alorabi, M., Ayyad, M., \& Sultan, E. A. (2020). Knowledge, perceptions, and attitude of Egyptians towards the novel coronavirus disease (COVID- 19). Journal of Community Health, 45(5), 881-890. https://doi.org/10.1007/s10900-020-00827-7

Adams, M. K., Salazar, E., \& Lundgren, R. (2013). Tell them you are planning for the future: gender norms and family planning among adolescents in northern Uganda. International Journal of Gynecology \& Obstetrics, 123, e7-e10. https://doi.org/10.1016/j.ijgo.2013.07.004

Babalola, S., Krenn, S., Rimal, R., et al. (2020). KAP COVID Dashboard. Johns Hopkins Center for Communication Programs, Massachusetts Institute of Technology, Global Outbreak Alert and Response Network, Facebook Data for Good. 2020. https://ccp.jhu.edu/kap-covid/. Accessed March 20, 2021.

Bukuluki, P., Mwenyango, H., Katongole, S. P., Sidhva, D., \& Palattiyil, G. (2020). The socio-economic and psychosocial impact of Covid-19 pandemic on urban refugees in Uganda. Social Sciences \& Humanities Open, 2(1), 100045. https://doi.org/10.1016/j.ssaho.2020.100045

Dyer, J., Wilson, K., Badia, J., Agot, K., Neary, J., Njuguna, I., ... \& Kohler, P. (2021). The psychosocial effects of the COVID-19 pandemic on youth living with HIV in Western Kenya. AIDS and Behavior, 25(1), 68-72. https://doi.org/10.1007/s10461-020-03005-x

Feyisa, Z. T. (2021). Factors limiting youths' practice of preventive measures toward the outbreak of COVID-19 in Oromia special zone surrounding Finfinnee, Ethiopia. Plos One, 16(3). https://doi.org/10.1371/journal.pone.0248495

Lindberg, L. D., Bell, D. L., \& Kantor, L. M. (2020). The Sexual and Reproductive Health of Adolescents and Young Adults During the COVID-19 Pandemic. Perspectives on Sexual and Reproductive Health. https://doi.org/10.1363/psrh.12151

Linnemayr, S., Mayo-Wilson, L. J., Saya, U., Wagner, Z., MacCarthy, S., Walukaga, S., ... \& Karamagi, Y. (2021). HIV care experiences during the COVID-19 pandemic: Mixed-methods telephone interviews with clinicenrolled HIV-infected adults in Uganda. AIDS and Behavior, 25(1), 28-39. https://doi.org/10.1007/s10461-020-03032-8

MacCarthy, S., Saya, U., Samba, C., Birungi, J., Okoboi, S., \& Linnemayr, S. (2018). "How am I going to live?": exploring barriers to ART adherence among adolescents and young adults living with HIV in Uganda. BMC Public Health, 18(1), 1-11. https://doi.org/10.1186/s12889-018-6048-7

Matovu, J. K., Kabwama, S. N., Ssekamatte, T., Ssenkusu, J., \& Wanyenze, R. K. (2021). COVID-19 Awareness, Adoption of COVID-19 Preventive Measures, and Effects of COVID-19 Lockdown Among Adolescent Boys and Young Men in Kampala, Uganda. Journal of Community Health, 1-12. https://doi.org/10.1007/s10900-021-00961-w 
$\mathrm{MOH}$ - Ministry of Health. Coronavirus (pandemic) COVID-19. Retrieved June 5, 2021, from https://www.health.go.ug/covid/

Nagata, J. M. (2020). Supporting young adults to rise to the challenge of COVID-19. Journal of Adolescent Health, 67(2), 297-298. https://doi.org/10.1016/j.jadohealth.2020.04.020

Ningsih, O. S., Eka, A. R., \& Danal, P. H. (2020). Factors Predicting Adolescents' Compliance on Covid-19 Prevention Protocols. Indonesian Nursing Journal of Education and Clinic (INJEC), 6(1), 55-63. https://doi.org/10.24990/injec.v6i1.365

Olum, R., Chekwech, G., Wekha, G., Nassozi, D. R., \& Bongomin, F. (2020). Coronavirus disease-2019: knowledge, attitude, and practices of health care workers at Makerere University Teaching Hospitals, Uganda. Frontiers in Public Health, 8, 181. https://doi.org/10.3389/fpubh.2020.00181

Oosterhoff, B., Palmer, C. A., Wilson, J., \& Shook, N. (2020). Adolescents' motivations to engage in social distancing during the COVID-19 pandemic: associations with mental and social health. Journal of Adolescent Health, 67(2), 179-185. https://doi.org/10.1016/j.jadohealth.2020.05.004

Orgilés, M., Morales, A., Delvecchio, E., Mazzeschi, C., \& Espada, J. P. (2020). Immediate psychological effects of the COVID-19 quarantine in youth from Italy and Spain. Frontiers in Psychology, 11, 2986. https://doi.org/10.3389/fpsyg.2020.579038

Shereen, M. A., Khan, S., Kazmi, A., Bashir, N., \& Siddique, R. (2020). COVID-19 infection: Origin, transmission, and characteristics of human coronaviruses. Journal of Advanced Research, 24, 91-98. https://doi.org/10.1016/j.jare.2020.03.005

Sherrard-Smith, E., Hogan, A. B., Hamlet, A., Watson, O. J., Whittaker, C., Winskill, P., ... \& Churcher, T. S. (2020). The potential public health consequences of COVID-19 on malaria in Africa. Nature Medicine, 26(9), 1411-1416. https://doi.org/10.1038/s41591-020-1025-y

Small, E., Nikolova, S. P., Zhou, Y., \& Okumu, M. (2021). Exploring factors associated with HIV secondary stigma among adolescents and young adults in Uganda: A cross-sectional study. Global Public Health, 1-12. https://doi.org/10.1080/17441692.2020.1869286

U-LEARN. (2020). COVID-19 Risk Communication and Community Engagement (RCCE) Assessment. Kampala Uganda. Retrieved April 17, 2021, from https://ulearn-uganda.org/download/covid-19-risk-communication-and-community-engagementrcce-assessment/

Usman, I. M., Ssempijja, F., Ssebuufu, R., Lemuel, A. M., Archibong, V. B., Ayikobua, E. T., ... \& Kasozi, K. I. (2020). Community drivers affecting adherence to WHO guidelines against covid-19 amongst rural Ugandan market vendors. Frontiers in Public Health, 8, 340. https://doi.org/10.3389/fpubh.2020.00340

Varol, T., Crutzen, R., Schneider, F., Mesters, I., Ruiter, R. A., Kok, G., \& ten Hoor, G. (2021). What to target when reopening universities in times of COVID-19? Selecting relevant and changeable determinants and underlying beliefs of university students' adherence to COVID-19-guidelines. [Preprint].

World Health Organization - WHO. (2020). WHO Director-General's Opening Remarks at the Media Briefing on COVID- 19 - 11 March 2020. Retrieved March 25, 2021, from https://www.who.int/dg/speeches/detail/who-director-general-s-opening-remarks-at-the-media-briefing-on-c ovid-19-11-march-2020. Accessed.

World Health Organization - WHO. (2021). COVID 19 Situational Report 62. Retrieved March 25, 2021, from https://www.who.int/emergencies/diseases/novel-coronavirus-2019/situation-reports

Zhong, B. L., Luo, W., Li, H. M., Zhang, Q. Q., Liu, X. G., Li, W. T., \& Li, Y. (2020). Knowledge, attitudes, and practices towards COVID-19 among Chinese residents during the rapid rise period of the COVID-19 outbreak: a quick online cross-sectional survey. International Journal of Biological Sciences, 16(10), 1745. https://doi.org/10.7150/ijbs.45221

\section{Copyrights}

Copyright for this article is retained by the author(s), with first publication rights granted to the journal.

This is an open-access article distributed under the terms and conditions of the Creative Commons Attribution license (http://creativecommons.org/licenses/by/4.0/). 